\title{
Colheita fracionada melhora a qualidade e longevidade do sêmen de garanhões sensíveis à refrigeração
}

Sidnei Nunes de Oliveira", Luis Fernando Mercês Chaves Silva, Endrigo Adonis Braga de Araujo, Luiz Roberto Pena Andrade Junior, Lucas Troncarelli Rodrigues, Patricia de Mello Papa,João Alexandre Matos Carneiro, Felipe Pires Hartwig, Marco Antonio Alvarenga, Marcio Teoro do Carmo, Camila Paula Freitas-Dell'Aqua, Jose Antonio Dell'Aqua Junior, Frederico Ozanam Papa

Universidade Estadual Paulista(UNESP), Botucatu, SP, Brasil

*Autor correspondente

e-mail: sidneino@gmail.com

\section{Resumo}

Garanhões cujo sêmen apresenta baixa resistência ao processo de refrigeração são denominados sensíveis à refrigeração. Este fato pode estar relacionado à ação exercida pelo plasma seminal nas células espermáticas, reduzindo a motilidade e fertilidade dos espermatozoides. Por conseguinte, a centrifugação do sêmen e posterior retirada do plasma seminal é necessária neste grupo de animais, por outro lado, este processo pode causar danos mecânicos às células espermáticas. Durante a ejaculação, o garanhão emite de cinco a nove jatos, divididos em três frações que se diferem pela sua composição e produção das glândulas sexuais acessórias. Uma técnica que pode proporcionar um menor efeito deletério às células espermáticas durante a refrigeração seria a técnica de colheita fracionada do ejaculado equino, pela qual é possível separar os primeiros jatos de sêmen, os quais possuem uma menor quantidade de plasma proveniente das vesículas seminais, tornando-se uma alternativa para minimizar os danos que possivelmente são provocados pelo plasma seminal, bem como pela centrifugação em garanhões considerados sensíveis à criopreservação. 0 objetivo deste trabalho foi comparar as diferentes frações do ejaculado em garanhões classificados como sensíveis e resistentes à refrigeração na manutenção da sobrevivência dos espermatozoides, avaliados pela cinética espermática após a refrigeração por $24 \mathrm{~h}$ a $5^{\circ} \mathrm{C}$. Para isso, colheu-se 10 ejaculados fracionados de garanhões que apresentaram queda na motilidade progressiva $\geq 25 \%$ após a refrigeração, classificados como sensíveis à refrigeração, e 10 ejaculados fracionados de garanhões cuja motilidade progressiva teve queda de $\leq 10 \%$ após a refrigeração, classificados como resistentes à refrigeração. As colheitas foram realizadas utilizando uma vagina artificial de dimensões modificadas e utilizando uma mucosa plástica, a qual denominou-se de Sperm clean, sendo as frações separadas em: "Fração A" (FA), correspondente ao $1^{0}$ e $2^{\circ}$ jatos do sêmen; "Fração B" (FB), correspondente ao 3o e $4^{\circ}$ jatos; e "Fração C" (FC), correspondente ao $5^{\circ}$ e os demais jatos do ejaculado. Após as colheitas, retirou-se uma alíquota correspondente a $33 \%$ 
do volume de cada uma das frações para formar o grupo controle/fração ejaculado FE. De cada uma das frações (FA, FB, FC e FE) de cada grupos de garanhões, retirou-se uma amostra e diluída em meio à base de leite (Botu-Sêmen ${ }^{\circledR}$ ) na concentração de 50 espermatozoides $/ \mathrm{mL}$, armazenadas em caixas para refrigeração (Botu-flex ${ }^{\circledR}$ ) e mantidas por 24 horas a $5^{\circ} \mathrm{C}$. Após $24 \mathrm{~h}$, as amostras foram submetidas à avaliação da cinética espermática computadorizada (Hamilton-ThorneTM) para motilidade total (MT), motilidade progressiva (MP) e percentual de espermatozoides rápidos (RAP). Os dados foram submetidos ao teste KolmogorovSmirnov para verificar a normalidade. Quando não apresentavam distribuição normal, utilizou-se o Friedman test seguido de teste de Dunns; para todos foi considerando $\mathrm{P}<0,05$ e expressados as médias e erro padrão, utilizando o pacote estatístico disponível no GraphPadInstat 5.0 software (San Diego, CA, USA). Os resultados demonstraram diferença estatística para o grupo de garanhões sensíveis para os parâmetros de MT, MP e RAP, entre as frações dos ejaculados após $24 \mathrm{~h}$ de refrigeração a $5^{\circ} \mathrm{C}$. Já para o grupo de garanhões resistentes houve diferença entre as frações na MT e MP, entre as frações dos ejaculados após $24 \mathrm{~h}$ de refrigeração a $5^{\circ} \mathrm{C}$. Desta forma, pode-se concluir que a fração A do ejaculado, a qual possui uma menor quantidade de plasma seminal produzido pelas vesículas seminais nos garanhões sensíveis à refrigeração, demonstrou uma melhor longevidade após a refrigeração a $5^{\circ} \mathrm{C}$ por $24 \mathrm{~h}$ e possibilitou uma melhor resistência espermática ao processo de criopreservação.

Palavras-chave: Criopreservação. Ejaculado fracionado. Espermatozoides.

Agradecimentos: à FAPESP pela concessão da bolsa de mestrado (no 2014/00354-0) e à Botupharma pelo fornecimento de meios diluentes. 